\title{
Dynamic Effects of Moving Loads on the Jointed Plain Concrete Pavement Responses
}

\author{
Gholam Ali Shafabakhsh ${ }^{1, a,{ }^{*}}$, Masoud Vafaei ${ }^{1, b}$, Nadia Amiri $^{2, c}$, and Afshin Famili ${ }^{3, d}$ \\ 1 Department of Civil Engineering, Semnan University, Semnan, Semnan 35131-19111, I.R. of Iran \\ 2 Department of Civil Engineering, Islamic Azad University Kashmar Branch, Kashmar, I.R. of Iran \\ 3 Department of Civil Engineering, Clemson University, Clemson, SC, USA \\ E-mail:ashafabakhsh@semnan.ac.ir (Corresponding author),bmasoud.vafaei65@gmail.com, \\ cnadiaamiri694@yahoo.com,dafshinf@g.clemson.edu
}

\begin{abstract}
In this paper, to analyze the Jointed Plain Concrete Pavement (JPCP), a 3-D dynamic model of the pavement was modeled using ABAQUS. Moving load with different speed and interaction between the Dowel bar and concrete has been considered in this research. The output for the strain in the joints has been validated with accurate experimental results. Research has shown that the finite element analysis, is an accurate and efficient method to model the interaction between the dowel bar and surrounding concrete. The results showed that with increasing the speed of moving load, the maximum strain in joints decreases. Such reduction is about $18 \%$ for the 20 ton axial load and the speed of $120 \mathrm{~km} / \mathrm{hr}$. relative to the speed of $32 \mathrm{~km} / \mathrm{hr}$. In addition, with increasing the axial load, the maximum strain in the joints increases. This increase is more for the lower speeds. In addition, it is found that decreasing the loading speed and increasing the axial load will result in increasing the maximum strain and maximum stress in the connected area of dowel bar and surrounding concrete. Thus it may become more than the ultimate tensile strength and result in initiate cracking in the tensile area of concrete slab, especially in the joints. Furthermore, the results showed that changing the mechanical specification of concrete would not significantly affect the maximum strain in the JPCP, which using $\mathrm{C} 50$ instead of $\mathrm{C} 25$, the maximum strain would increase about $10 \%$. However, the mechanical specification of JPCP could affect the cracking propagation and concrete durability.
\end{abstract}

Keywords: JPCP, finite element, moving load.

ENGINEERING JOURNAL Volume 21 Issue 5

Received 26 September 2016

Accepted 13 March 2017

Published 29 September 2017

Online at http://www.engj.org/

DOI:10.4186/ej.2017.21.5.137 


\section{Introduction}

Jointed Plain Concrete pavement (JPCP) are constructed of Portland cement concrete and composed of numerous discrete concrete slabs, longitudinal and transverse joints, and dowels. Although transverse joints are used to control cracks regarding to thermal deformation and drying shrinkage of the slabs, application of these joints may decrease the load carrying capacity of the concrete slabs near the edge. That reduction should be controlled to prevent pavement damage under repeated wheal load [1].

There are various methods for evaluating the structural capacity of pavements from deflection basin data including non-destructive testing (i.e. FWD testing) techniques and numerical and analytical programs (i.e. statistical regression analysis, closed-form solutions, ISLAB2000, DIPLOMAT, KENSLABS finite element programs, EverCALC 5.0, BAKFAA, EverFE 2.24 pavement backcalculation programs), which most of them focused on the amount of load transfer across a dowelled joints. With the development of computational mechanics, the finite element method and the boundary element method broke the limitations of boundary conditions and load types in analytical methods [2]. Several researches applied finite element method (FEM) as one the most accurate and powerful numerical tool to investigate the pavement layer properties and critical pavement responses in-depth under traffic and environmental loading conditions.

\section{Literature Review}

The size and location of vehicle loads can be time-dependent. Based on Kim et al., the dynamic loads imposed by moving vehicles have variations in load magnitude due to the surface roughness of the pavement system and larger dynamic loads than the design loads can affect the pavement performance and life [3]. As a result, two different methods are used in pavement analysis.

Hendrick et al. [4], simulated a moving load in which a uniform contact pressure is moving at a constant speed on a straight line in the longitudinal direction of the concrete slab. In the second procedure, Kim et al. evaluated pavement roughness profiles along the wheels path and truck suspension. For this purpose, they estimated the load time history and then the analysis has been conducted using the time history of axle load integral. Comparison between the failure rates of the first and second methods by Hendrick et al. [4] showed that the second approach, after 15 years lifespan of the pavement, leading to cracking due to fatigue will be approximately $38 \%$ larger than the first method. They also found that if one considers the constant moving loads, in the area near the joints, severe damage will be witnessed. On the other hand, using the load time history, reduces cracking at the corner about $15 \%$ and dramatically increases the cracking at the middle edges. In addition, these results are influenced by the speed of the truck $[4,5]$.

Chatti et al. [6] formulated the dynamic solution (moving load method) in both the time and frequency domains. Subgrade layer represented by either a damped Winkler model with uniformly distributed frequency dependent springs and dashpots or a system of semi-infinite horizontal layers resting on a rigid base. The results indicated that quasi-static models are sufficient and conservative, which the wheal load adjustment has been considered for the effects of vehicle velocity, truck suspension characteristics, and pavement roughness.

Kim [7] modeled the frictional contact interface between the concrete slab and supporting layer in order to enhance the accuracy of finite element solution with solid elements. Their approach could directly evaluate the amount of load transfer across doweled joint by computing the shear force in the beam elements. Based on the results, 15 to $30 \%$ of the applied wheel load were transferred to the adjacent slab segment by the dowels, which varied in accord with design and loading conditions. Furthermore, 95\% of the transferred shear force is carried only by the nine or eleven dowels which were closest to the applied load. In addition, the other approach conducted by Shafabakhsh et al. [8] focused on the stress, strain and deformation in pavement under traffic loads for asphalt concrete pavement. The results indicated that in static and quasi-static loadings, the maximum strain were observed exactly under the load center, while in dynamic loading, unexpectedly, the maximum value occurred behind the load center, and the distance increases by increase of vehicle velocity.

AASHTO [9] test used single axle vehicles with a load between $54.432 \mathrm{KN}$ and $136.08 \mathrm{KN}$ to study dynamic effects of moving loads on the pavement responses. The results indicated that an increase in truck 
speed from $3.22 \mathrm{~km} / \mathrm{hr}$ to $96.558 \mathrm{~km} / \mathrm{hr}$ decreases the magnitude of induced tensile stress and deflection in the concrete slabs by about 29 percent.

Uddin et.al [10] conducted a research using finite element to investigate the effects of pavement discontinuities on the surface deflection response of a jointed plain concrete pavement. They develop a 3D model with an appropriate boundary conditions in their research. The results showed an improvement over the multi-layered linear static analysis.

From the previous researches, it could be noticed that there is a lack of coordination among the results for the response of concrete pavement under dynamic loads. It seems that more future research should be conducted in order to achieve a brighter and additional instructions on dynamic analysis of concrete pavements.

\section{Methodology}

In this study, three-dimensional finite element model for JPCP has been analyzed using ABAQUS 6.11 as a powerful and useful tool for evaluating load carrying capacity of the concrete slabs near the edge. In addition to the interaction between dowel bar and concrete slab, the effect of post-slip horizontal displacement has been considered during the analysis. In this paper, the dynamic loads with different speeds has been modeled, considering the effect on the pavement. Finally, the effect of axial load and speed of the vehicle on the maximum vertical displacement applied to the pavement edge has been examined.

\subsection{Dynamic Analysis of Rigid Pavement Parameters}

Vehicle loads, which are applied to the concrete slabs with different speeds along the road, are inherently dynamic. As a result, the size and location of vehicle loads can be time-dependent. Transient dynamic time (also known history analysis), is a technique for determining the dynamic response of a structure under time-dependent loads.

The basic equation of motion solved by an implicit transient dynamic analysis can be given as Eq. (1):

$$
[M]_{(t)}\{\ddot{X}\}_{(t)}+\left[C_{d}\right]_{(t)}\{\dot{X}\}_{(t)}+\left[K_{s}\right]_{(t)}\{X\}_{(t)}=\{F(t)\}
$$

where $[M]_{(t)}$ is the mass matrix in the time $t ;\left[C_{d}\right]_{(t)}$ is the damping matrix in the time $t ;\left[K_{s}\right]_{(t)}$ is the stiffness matrix in the time $\mathrm{t} ;\{\ddot{\mathrm{X}}\}_{(\mathrm{t})}$ is the acceleration vector in the time $\mathrm{t} ;\{\dot{\mathrm{X}}\}_{(\mathrm{t})}$ is the velocity vector in the time $\mathrm{t} ;\{\mathrm{X}\}_{(\mathrm{t})}$ is the position vector in the time $\mathrm{t}$; and $\mathrm{F}(\mathrm{t})$ means the load vector. This application can be extended to all the nodes of rigid pavement. If there is a balance between the applied load and reaction loads included, the pavement will assumed to be sustainable. At any given time t, this equation can be regarded as a set of "static" equilibrium equations, which can also take into account inertia forces $[\mathrm{M}]_{(\mathrm{t})}\{\ddot{\mathrm{X}}\}_{(\mathrm{t})}$ and damping forces $\left[\mathrm{C}_{\mathrm{d}}\right]_{(\mathrm{t})}\{\dot{\mathrm{X}}\}_{(\mathrm{t})}[13]$.

Several methods have been proposed to determine the stiffness and damping matrices. Nowadays finite element software assist users to determining these matrixes simpler than before. Riley provides an equation which predicts the damping matrix based on mass and stiffness matrix (see Eq. (2)) [13].

$$
\left[C_{d}\right]=[M]+\beta_{R}\left[K_{s}\right] \alpha_{R}
$$

where $\alpha_{\mathrm{R}}$ and $\beta_{\mathrm{R}}$ are Riley constants and can be calculated based on damping ratio $\left(\xi_{\mathrm{i}}\right)$.

\subsection{Model Assumption}

To analyze the linear three-dimensional, elastic pavement layers are taken into account to analyze the linear 3-D model. In addition, a solid foundation is assumed to model subgrade layer. Three layers including concrete slabs, base and subgrade has been considered in the model.

Pavement layer and dowel bars properties and dimensions used in model is represented in Table 1. 
Table 1. Material and layers properties.

\begin{tabular}{lllll}
\hline Layer & Dimension $(\mathbf{m})$ & Elasticity module $\mathbf{( M P a )}$ & Poisson ratio & Density $\mathbf{( K g} / \mathbf{m} 3)$ \\
\hline Concrete slabs & $0.26 * 4.5 * 5$ & 30000 & 0.15 & 2400 \\
Base & $0.2 * 5.5 * 11.1$ & 800 & 0.3 & 2000 \\
Subgrade & $2 * 5.5 * 11.1$ & 150 & 0.35 & 2100 \\
Dowel bar & f0.032 & 210000 & 0.3 & 7800 \\
\hline
\end{tabular}

Despite Kirchhoff plate elements, solid elements can represents the strain and displacement changes in concrete slabs under loading accurately. In addition solid element is used to model the subgrade to consider heterogeneous properties of the layer. Frictional contact has been used for the interaction between the dowel bar and concrete slabs. Different mesh size has been checked using trial and error method, so the borderline have no effect on the results of the analysis.

Defining of small and triangular mesh is necessary to obtain accurate results in the loading region. However, for the other areas of the pavement away from the edge larger mesh is used to reduce the analysis time [11].

Concrete slab and the layers are interconnected by frictional contact. The value of this friction is considered 0.05. Connecting the base layer and the substrate is defined as bonded [7]. Dowell bars are all uniform on one side and on the other by frictional contact (assumed to be 0.1 ) with bonded contact [12].

\section{Model Validation}

In this study the model is validated with valid experimental data and numerical studies [11]. In this test the load time axis with double wheels, two levels of load area as shown in Fig. 1 was considered as static. For the analysis of the tandem axle load, two wheel loads are applied as static loads at the position as shown in Fig. 1 [11].

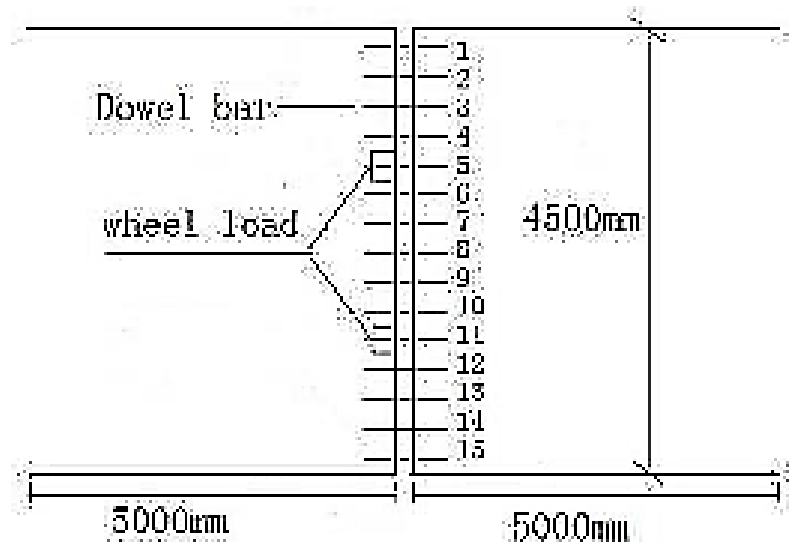

Fig. 1. Wheel load position in the model [5].

\subsection{Geometry of Finite Element Model}

The finite element model consists of two concrete slabs, dowel bars embedded in the slabs, a base layer and subgrade. The joint width assumed to be $5 \mathrm{~mm}$ between two concrete slabs for free expansion and contraction. The model consists of 15 dowel bars in the middle of the slab with $30 \mathrm{~cm}$ joints (see Fig. 2). 


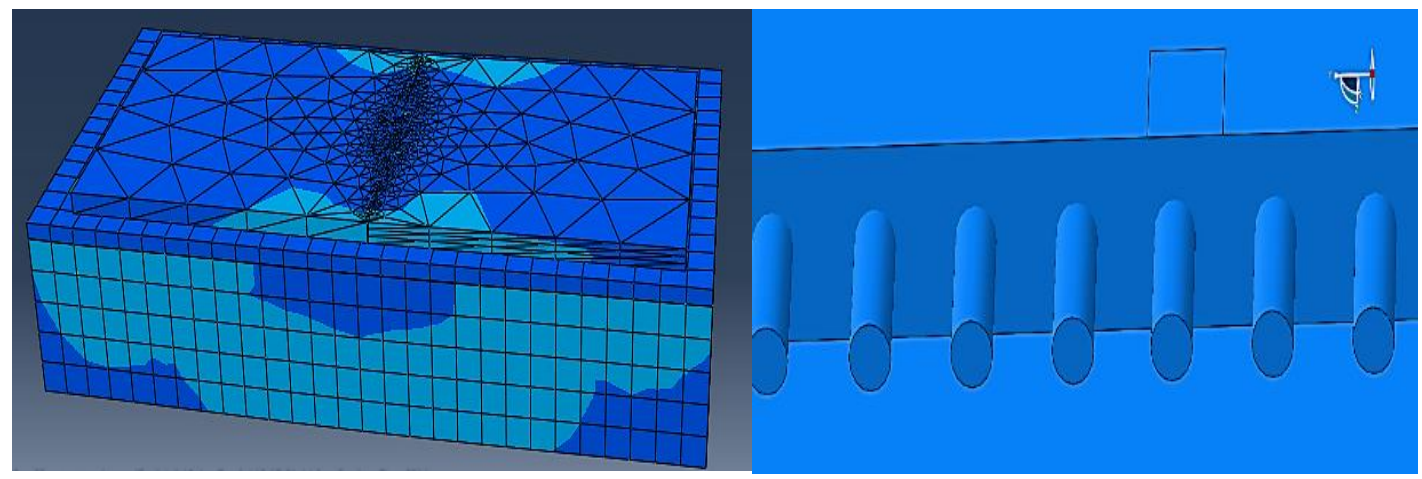

Fig. 2. 3-D finite element model of JPCP.

\subsection{Validation Results}

In order to simulate various load levels, three different values of tandem axial load double (10 tons, 20 tons and 30 tons) is used in this study. This load has a uniform distribution on a rectangular area with dimensions of $25 \times 35 \mathrm{~cm}$ [11].

Figure 3 represents a comparison of the maximum vertical displacement near the edge for the model of this research and a valid experimental and numerical results [11]. The figure shows that the maximum strain around dowel bars in this research is close to the experimental results with an acceptable error. Thus, the results of this study can be accurate and effective to simulate doweled joint performance.

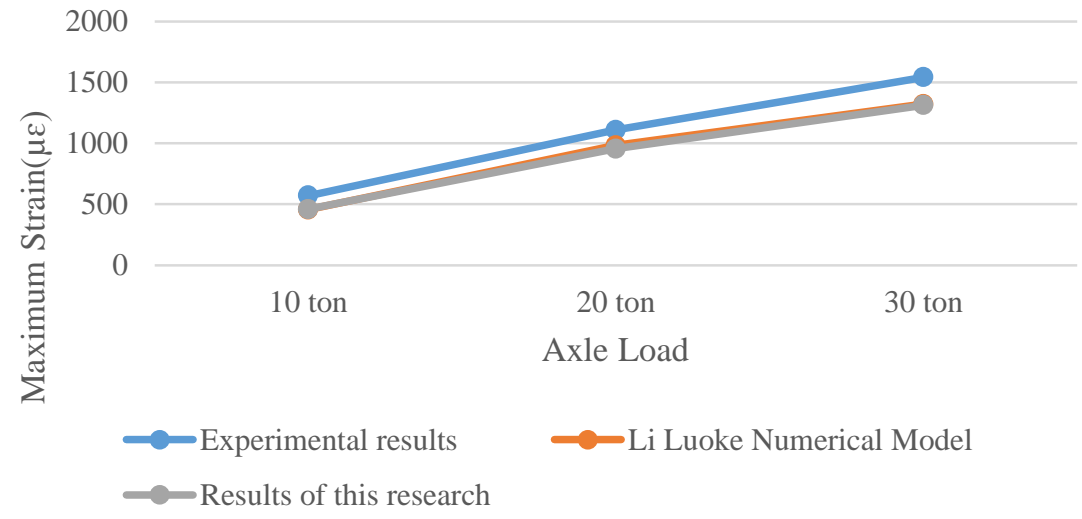

Fig. 3. Validation results.

\section{Results and Discussion}

Twelve finite element models has been simulated with three axle loads (10, 20 and 30 tons) and four different speed of 32, 56, 80 and 120 kilometers per hour. Loading direction is represented in Fig. 4. The load is simulated by applying a uniform contact pressure with constant speed on a straight line in the longitudinal direction of the concrete slab.

After performing the analysis, structural response (maximum strain) at pavement edge pavement is recorded. The results show that for different speeds if axle load increases, the maximum strain will also increase. The rates of increase for low and high speeds are about 70 and 80 percent respectively. In addition, increasing the speed will result in decrease in the maximum strain at the pavement edge under each axle loads. It is calculated that the maximum strain for 120 and 32 kilometers per hour is 579 and 709 microstrain respectively. Therefore, there is 18 percent reduction in maximum strain when the velocity changes from 120 to 32 kilometers per hour. Figure 5 represented the relation between maximum strain and different speeds. 


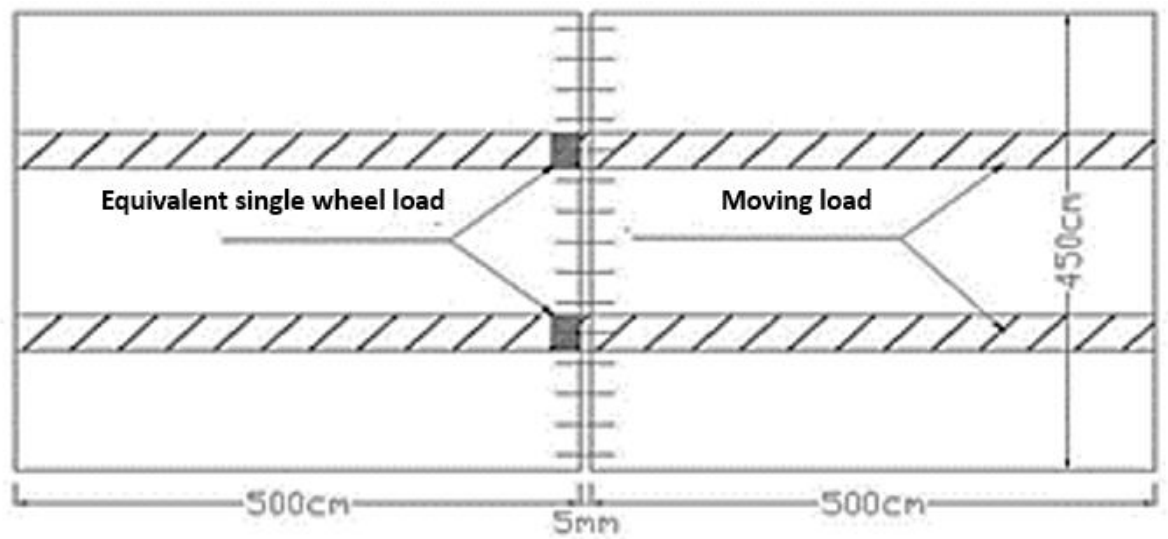

Fig. 4. Moving load area in dynamic analysis of JPCP.

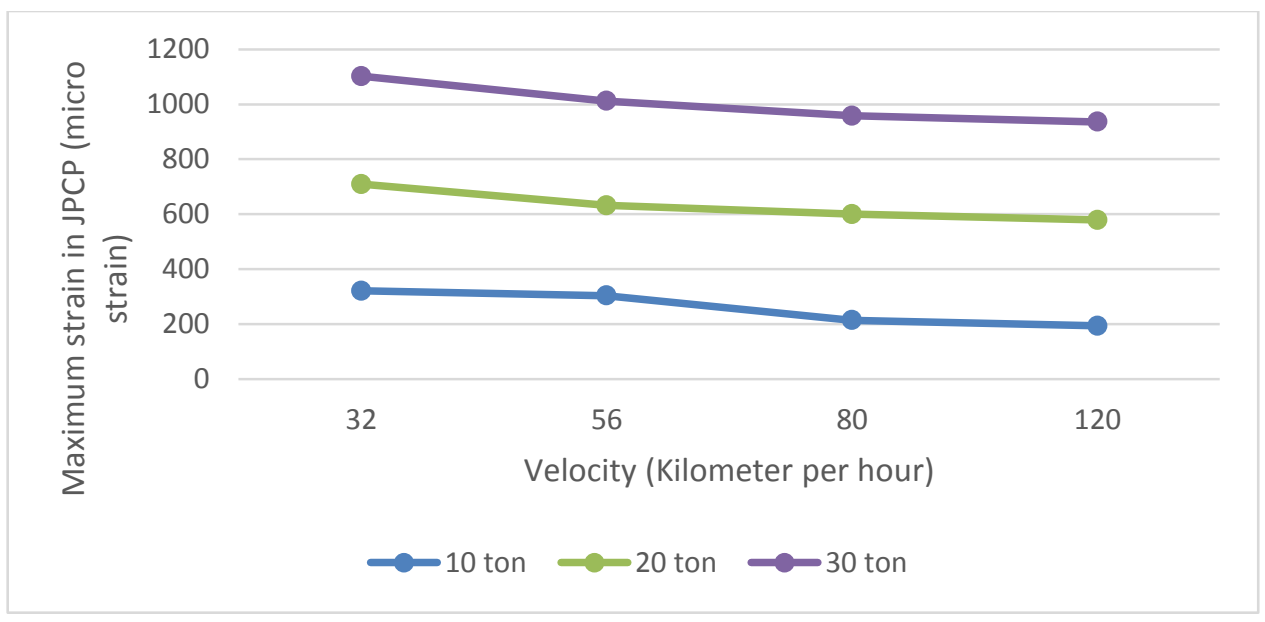

Fig. 5. Maximum strain in JPCP results for different velocities.

In addition, seven finite element model based on seven different values for modulus of elasticity of concrete has been considered for axle weight was 20-ton axle weight. Figure 6 represents the pavement strain response under different values of modulus of elasticity. The results show that an increase in modulus of elasticity of concrete will result in reduction of maximum strain.

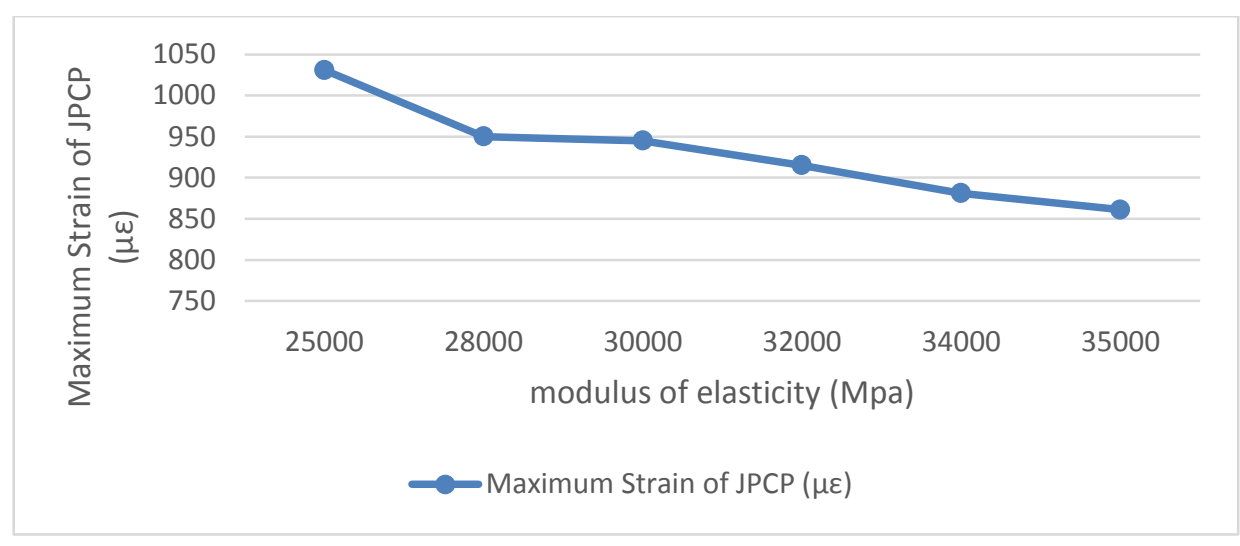

Fig. 6. The effect of modulus of elasticity of concrete on maximum strain in JPCP.

Regarding to Eq. (3) and assuming normal weight for concrete $\left(2400 \mathrm{~kg} / \mathrm{m}^{3}\right)$ in the model, the effect of mechanical specification of concrete could be compared with the pavement response. 


$$
E_{c}=\left(3300 \sqrt{f_{c}}+6900\right)\left(\frac{\gamma_{c}}{2300}\right)^{1.5}
$$

Figure 7 shows the effect of mechanical specification of concrete in JPCP on maximum strain. The results showed that changing the mechanical specification of concrete would not significantly affect the maximum strain in the JPCP, which using C50 instead of C25, the maximum strain would increase about 10 $\%$. However, the mechanical specification of JPCP could affect the cracking propagation and concrete durability.

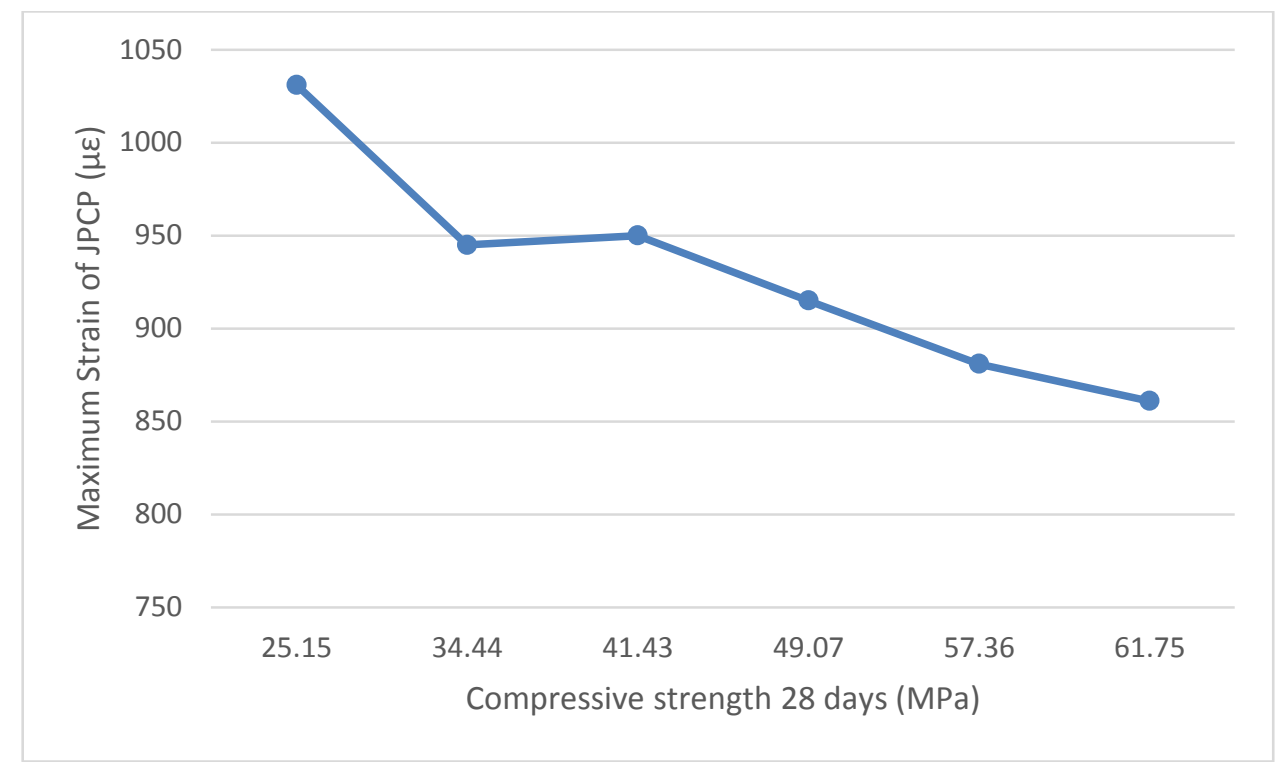

Fig. 7. The effect of mechanical specification of concrete on maximum strain in JPCP.

\section{Conclusion}

In this paper, to analyze JPCP, a 3-D dynamic model of the pavement was modeled using ABAQUS and the pavement response of the model were validated, using experimental data. The results are summarized as bellow:

1. Dynamic analysis conducted on JPCP has shown that moving loads and vehicle speeds have significant impact on pavement response. The results suggests that the tensile stress and strain under dynamic loads is less than the static loads. Hence, the design based on static loading could be more reliable.

2. Vehicle axle load could have significant impact on maximum strain of JPCP, especially at the interaction between dowel bars and concrete, where increasing the axle load will result in increasing the maximum strain of the pavement for different speeds. Based on the results, the rate of increase for low speeds to high speeds are approximately 70 percent and 80 percent.

3. Under each passing axle loads the stress and strain at joints will be by increasing the vehicle speed. The results showed an approximately 18 percent reduction in the strain for changing the vehicle speed from $120 \mathrm{~km} / \mathrm{hr}$ to $32 \mathrm{~km} / \mathrm{hr}$.

4. The maximum strain at lower speeds would decrease with the rate more than higher speeds, where the decline is approximately 10 percent for speeds of $32 \mathrm{~km} / \mathrm{hr} 56 \mathrm{~km} / \mathrm{hr} 10 \%$ and 2 percent for $96 \mathrm{~km} / \mathrm{hr}$ and $120 \mathrm{~km} / \mathrm{hr}$. The percentage of this reduction is negligible at high speeds and optimal speed to achieve the least amount of damage could be considered between 80 and $120 \mathrm{~km} / \mathrm{hr}$.

5. With decreasing the speed and increasing the passing axle load maximum strain and subsequently the maximum stress in the interaction between dowel bar and the concrete will reach the ultimate tensile strength of concrete, which began cracking in tensile area of concrete slab, especially at the joints.

6. Changing the mechanical specification of concrete would not significantly affect the maximum strain in the JPCP, which using C50 instead of C25, the maximum strain would increase about 
$10 \%$. However, the mechanical specification of JPCP could affect the cracking propagation and concrete durability.

\section{References}

[1] Division of Design, "Guide for design and construction of new jointed plain concrete pavements (JPCPs)," Office of Pavement Design Pavement Design \& Analysis Branch, 2008.

[2] P. Cao, C. Zhou, D. Feng, Y. Zhao, and B. Huang, "A 3D direct vehicle-pavement coupling dynamic model and its application on analysis of asphalt pavement dynamic response," Mathematical Problems in Engineering, pp.1-8, 2013.

[3] S. M. Kim, S. K. Rhee, H. B. Park, and D. J. Yun, "Correlations among pavement surface roughness, moving dynamic vehicle loads, and concrete pavement performance," in Performance Modeling and Evaluation of Pavement Systems and Materials: Selected Papers from the 2009 GeoHunan International Conference ASCE, July 2009, pp. 25-31.

[4] J. K. Hendrick, M. J. Marlow, and B. Bradmeyer, The Simulation of Vehicle Dynamic Effects on Road Pavements. McLean, VA: Federal Highway Administration, 1992.

[5] M. Y. Darestani, "Response of concrete pavements under moving vehicular loads and environmental effects," Ph.D. thesis, Centre of Built Environment and Engineering Research, Queensland University of Technology, QLD, Australia, 2007.

[6] K. Chatti, J. Lysmer, and C. L. Monismith, "Dynamic finite-element analysis of jointed concrete pavements," University of California Transportation Center, 1994.

[7] J. Kim, "Three-dimensional finite element analysis of multi-layered system: Comprehensive nonlinear analysis of rigid airport pavement systems," Department of Civil Engineering, University of Illinois at Urbana-Champaign, 2000.

[8] G. Shafabakhsh, H. Naderpour, \& M. Motamedi, "Dynamic analysis and determination of maximum tensile strain of bottom asphalt concrete for different vehicle velocities," Engineering Journal, vol. 19, no. 4, pp. 107-116, 2015.

[9] AASHTO, "Guide for mechanistic-empirical design of new and rehabilitated pavement structures," Appendix QQ-Structural Response Models for Rigid Pavements, National Cooperative Highway Research Program, Transportation Research Board, National Research Council, 2003.

[10] W. Uddin, R. M. Hackett, A. Joseph, Z. Pan, and A. B. Crawley, "Three-dimensional finite-element analysis of jointed concrete pavement with discontinuities, Transportation Research Record, vol. 1482, pp. 26-32, 1995.

[11] L. Luoke, T. Yiqiu, G. Xiangbing, and L. I. Yunliang, "Characterization of contact stresses between dowels and surrounding concete in jointed concrete pavement," International Journal of Civil \& Environmental Engineering, vol. 12.5, pp. 23-27, 2009.

[12] W. G. Davids, Z. Wang, G. Turkiyyah, J. Mahoney, and D. Bush, "Three-dimensional finite element analysis of jointed plain concrete pavement with EverFE 2.2.," Transportation Research Record: Journal of the Transportation Research Board, (1853), pp.92-117, 2003.

[13] ANSYS, "Gudelines for integration time step," in ANSYS Help, section 5.9.1., 2006. 